\title{
Comunicação, esporte, turismo e meio ambiente: como a canoagem transformou Piraju em cidade olímpica*
}

\author{
Communication, sports, tourism and environment: how \\ canoeing transformed Piraju into an olympic town
}

\section{Comunicación, deporte, turismo y medio ambiente: cómo el piraguiismo transformó Piraju en una ciudad olímpica}

\section{Luciano Victor Barros Maluly}

- Doutor em Ciências da Comunicação pela Escola de Comunicações e Artes da Universidade de São Paulo (ECA-USP), com pós-doutorado pela Universidade do Minho (Portugal)

- Mestre em Comunicação Social pela Universidade Metodista de São Paulo (Umesp)

- Graduado Jornalismo pela Universidade Estadual de Londrina (UEL)

- Professor de Jornalismo na ECA-USP

- Autor da obra: Jornalismo: a democracia pelo rádio

- lumaluly@usp.br

\section{José Luiz Fernandes Cerveira Filho}

- Doutor em Ciências Sociais pela Universidade Federal de São Carlos (UFSCAR) Mestre em Sociologia Política pela Universidade Federal de Santa Catarina (UFSC)

- Graduado em Ciências Sociais pela Universidade Estadual de Londrina (UEL),

- Professor do Departamento de Ciências Sociais e coordenador do Programa de Pós-Graduação em Meio Ambiente e Desenvolvimento, na Universidade Federal do Paraná (UFPR).

-j_cerveira@ufpr.br

* Colaboraram para este texto o jornalista Gervásio Pozza Filho, diretor do Departamento de Turismo e Esportes Náuticos da Estância Turística de Piraju (SP), e Margareth Pillegi Mourão, turismóloga do mesmo departamento. 
Resumo

Este artigo apresenta um relato sobre a experiência que ocorre na estância turística de Piraju, no interior de São Paulo. O principal argumento é o de que esse município se transformou em cidade olímpica a partir da implantação de projetos esportivo-educacionais que intentam o desenvolvimento da canoagem. A integração entre esporte, comunicação e meio ambiente modificou as relações sociais na localidade, com impactos diretos no turismo e no bem-estar dos moradores. No bojo dessa situação, os resultados preliminares dessa política modificaram a rotina dos meios de comunicação na região.

PALAVRAS-CHAVE: COMUNICAÇÃO • ESPORTE • MEIO AMBIENTE • PIRAJU • TURISMO

Abstract

This article presents a report on the experience that occurs in the touristic city of Piraju, in the State of São Paulo. The main argument is that the municipality became an Olympic city as from the implementation of sports and educational projects that attempt to develop canoeing. The integration between the sport, communication and environment changed social relations in the locality, with direct impacts on tourism and the well-being of residents. Amidst this situation, the preliminary results of this policy changed the routine of the media in the region.

KEYSWORDS: COMMUNICATION • SPORT • ENVIRONMENT • PIRAJU • TOURISM

Resumen

Este artículo presenta un relato sobre la experiencia que ocurre en la estancia turística de Piraju, ciudad situada en el interior del estado de São Paulo. El principal argumento es el de que ese municipio se transformó en ciudad olímpica a partir de la implantación de proyectos deportivo-educacionales, que buscan el desarrollo del piragüismo. La integración entre deporte, comunicación y medio ambiente modificó las relaciones sociales en la localidad, con impactos directos en el turismo y en el bienestar de los habitantes. En el contexto de esa situación, los resultados preliminares de esa política modificaron la rutina de los medios de comunicación de la región.

PALABRAS CLAVE: COMUNICACIÓN • DEPORTES • MEDIO AMBIENTE • PIRAJU • TURISMO 
N as últimas duas décadas, dentre o conjunto de ações governamentais voltadas ao desenvolvimento social e econômico de regiões no interior do Brasil, é possível destacar uma série de políticas públicas destinadas a fomentar a indústria do turismo. Esse setor, no Brasil e no mundo, se consolida como uma importante atividade socioeconômica, apresentando altas taxas de crescimento que contribuem para o desejado desenvolvimento das regiões onde ocorre.

Nesse sentido, observa-se a necessidade de elaboração de políticas nacionais e estaduais de turismo que estejam postas de maneira diretamente relacionada com o local onde elas se desenvolverão, levando em consideração as condições favoráveis e as deficiências do município, além da situação populacional, principalmente quanto a sua cultura, seus hábitos e a sua história. Cada região, e, nela, cada município contêm suas peculiaridades, sendo o grande desafio do poder público conseguir viabilizar uma política pública de turismo que objetive a integração de todas as regiões em todas as esferas da governança ${ }^{1}$.

O objeto deste artigo é a região da Estância Turística de Piraju, cidade localizada no interior do Estado de São Paulo (figura 1) e considerada um dos pontos turísticos mais interessantes da região sudeste brasileira no que tange ao valor cênico e estético do conjunto formado por seus recursos naturais, culturais e, mais recentemente, esportivos. O município apresenta uma variedade de atrativos turísticos que vão desde cachoeiras, lagos e rios, até a arquitetura dos casarões existentes. O acervo cultural é representado pelos sítios arqueológicos, catalogados pelo Museu de Arqueologia e Etnologia (MAE) da Universidade de São Paulo (USP), que mantém na cidade o Centro de Arqueologia Ambiental Mário Neme².

Em meados da década de 1990, as potencialidades turísticas do município foram reconhecidas pelo governo do Estado de São Paulo, sendo-lhe concedido o status de estância turística ${ }^{3}$ pela Secretaria Estadual de Turismo. A resolução foi de grande importância para a cidade viabilizar projetos e acessar verbas públicas destinadas ao desenvolvimento regional, entre elas diversas verbas da Secretaria Estadual de Turismo e do Ministério do Turismo.

1 A ideia de governança, tal como é concebida na atualidade, evidencia a mútua e crescente relação das esferas do público e do privado. Baron (2003) pontua a dificuldade de postular uma definição única ou estabilizada para esse conceito, justamente devido à sua polissemia. Como exemplo, observa-se que as questões que demandam a possibilidade de gestão transitam ora pelo estado, ora pelas cidades, mas também pelas empresas e pelo mercado.

2 <http://www.usp.br/mapas/piraju.html>. Acesso em: 25/10/2011.

30 Estado de São Paulo subdivide-se em 645 municípios, dos quais 67 são considerados estâncias. São cidades que recebem verba do Departamento de Apoio ao Desenvolvimento das Estâncias (Dade). As estâncias são classificadas como balneárias, climáticas, hidrominerais e turísticas, sendo estas últimas cidades com muitas tradições culturais, patrimônio histórico, artesanato, lindas paisagens, centros de lazer, além de ótimos serviços de gastronomia. Fontes: Seade (2006).; <http://www.turismo.sp.gov.br/ dade/estancias.html > - acesso em: 26/10/2011. 
Pela grande disponibilidade de recursos hídricos presentes, desde meados do século passado - depois que parte do rio Paranapanema fora represado em seu trecho urbano -, o habitante da cidade revelou uma grande intimidade com esportes náuticos de alto desempenho, fosse a natação, o salto ou o esqui aquático. Também sempre foi destaque a presença de atividades de lazer com o uso de barcos, pedalinhos e canoagem de represa. Mais recentemente, a prática da canoagem foi ampliada, com a diversificação de modalidades, fato que transformou o destino do município. $\mathrm{O}$ acesso às verbas públicas e a disponibilização de variados incentivos e políticas de apoio para o desenvolvimento social e econômico viabilizaram a cidade como sede de treinamento para atletas de alta performance, incluindo a seleção brasileira.

O desenvolvimento dessa modalidade olímpica no município trouxe uma mudança no comportamento dos moradores, principalmente os jovens. Além de uma forma de lazer e de acesso seguro ao rio, a canoagem começou a ser observada como um meio de ascensão social, pelo reconhecimento e pela projeção que a categoria atingiu no município. Além disso, havia a chance, mesmo que pequena, de inserção no mercado de trabalho como atleta de alto rendimento.

A canoagem também tem modificado a atitude dos meios de comunicação locais - rádios, jornais e sites - que fazem a cobertura dos acontecimentos esportivos. Ao lado do futebol, a canoagem se destaca nas páginas e nos microfones dos principais noticiários.

Com a proximidade dos Jogos Olímpicos de 2012, em Londres, e mesmo da edição do Rio de Janeiro, em 2016, a experiência de Piraju é um exemplo para que o legado do evento no Brasil deixe marcas para o futuro, como aconteceu em Barcelona em 1992. A existência de uma modalidade ativa em municípios pequenos pode ser um caminho para o país se consagrar como uma potência esportiva.

Uma questão considerada de grande relevância para o desenvolvimento local das modalidades olímpicas é também o mais importante aspecto de diversas lutas socioambientais que têm ocorrido no município ${ }^{4}$. Em Piraju, os resultados de excelência dos esportes olímpicos, principalmente da canoagem de corredeira, reforçam a conservação do meio ambiente, notadamente pelo fato de a canoagem ser um esporte praticado em águas abertas, em relação direta com a natureza, e que precisa da manutenção dos locais quase intocados para existência da própria atividade 5 . Saliente-se ainda que a integração esporte, co-

4 Os locais utilizados para treino da equipe pirajuense de canoagem, bem como para a realização de provas em etapas de diversos campeonatos da modalidade, são amplamente desejados pelo setor hidroelétrico para a construção de uma Pequena Central Hidroelétrica (PCH).

5 À medida que os atletas da cidade foram obtendo conquistas, a imprensa local passou a divulgar as notícias procurando relacionar, por diversas vezes, o contrassenso que seria a degradação ambiental naquele local onde 0 esporte se desenvolve, entrando abertamente na defesa ambiental. 
municação e meio ambiente modificou as relações sociais de uma localidade, com impactos diretos no turismo e no bem-estar dos moradores.

A metodologia deste trabalho se caracteriza pela análise de documentos, observação da mídia local e visitas técnicas ao município, com os conceitos de meio ambiente e cobertura olímpica constituindo-se em ferramentas teóricas para a compreensão do impacto da prática da canoagem na região de Piraju.

\section{NOVOS RUMOS DA COMUNICAÇÃO ESPORTIVA}

Os valores olímpicos, como a excelência, a amizade e o respeito (COB, 2010), são difundidos entre os educadores, os atletas, os comunicadores, além de outras pessoas envolvidas com o esporte, como o público consumidor das notícias e de transmissões de eventos. O pesquisador Wilson Bueno (2009) alerta sobre a importância de uma divulgação e, por conseguinte, da compreensão do esporte:

O esporte não pode, sob nenhuma hipótese, ser visto como uma atividade imune à ação de outros interesses ou aspectos (econômicos, sociais, culturais, políticos) porque, sem isso, ele se descontextualiza e, certamente, vai ficar difícil entender porque algumas coisas nele ocorrem.

A mensagem do olimpismo (Tubino, 2007) é determinante na condução dos projetos comunicacionais relacionados ao movimento esportivo. O planejamento depende da postura das organizações (entre elas, secretarias, ministérios, federações, confederações, clubes e outras entidades) e do trabalho integrado entre as diversas áreas, em particular da comunicação, como explica a pesquisadora Isildinha Martins (2002, p. 20):

As organizações esportivas precisam entender que, apesar de dotadas do monopólio desportivo, são compreendidas pelos seus públicos como organismos vivos e, portanto, carentes de informação. A máxima "quem não é visto não é lembrado" aplica-se às organizações amorfas, acomodadas no poder que emana, esquecendo que os torcedores e os atletas e, consequentemente os investidores migram para 'marcas' fortes, organizadas, comunicativas e que valorizam seus públicos.

Para resultados positivos em comunicação é necessário estabelecer um padrão de trabalho, um plano de comunicação que possa delinear objetos, ações, estratégias, fluxos de comunicação, avaliações e realimentação.

Vale lembrar que as organizações de forma geral utilizam formas de comunicação advindas de técnicas do marketing, propaganda e publicidade, jornalismo, eventos, promoções e relações públicas. 
O processo de comunicação deve ser ordenado, a fim de permitir a perfeita sintonia entre os setores e/ou departamentos, gerando a comunicação integrada, sem esquecer, no entanto as implicações sociológicas, antropológicas, psicológicas e administrativas que permeiam as instituições e os indivíduos nela inseridos, além das interferências das diferentes culturas e das pressões do ambiente interno e externo dos indivíduos.

A comunicação esportiva tende a refletir também no atual modelo de cobertura midiática, que privilegia, principalmente, os eventos relacionados ao futebol masculino profissional. Pesquisadores do Banco Nacional de Desenvolvimento Econômico e Social (BNDES) desenvolveram um estudo que identifica a situação atual dos esportes no Brasil, com considerações preocupantes diante da comunicação, em particular, por causa do contraste entre o monopólio do futebol e a situação das demais modalidades:

O futebol concentra praticamente toda a atenção da população brasileira. As outras modalidades esportivas recebem cobertura marginal da mídia e de comentaristas esportivos. Alguns esportes, amplamente praticados em outros países, são elitizados no Brasil. Há poucas ações para reversão desse quadro e desenvolvimento de outras modalidades esportivas (Santos et al., 2007, p. 9).

Nesse contexto, é essencial fazer uma reflexão sobre o modelo de mídia aplicado no Brasil. Diariamente, diversos veículos disponibilizam conteúdos voltados prioritariamente aos principais campeonatos de futebol. Contudo, além dos campeonatos de futebol, o atual modelo de cobertura esportiva se constitui de eventos internacionais de automobilismo ou mesmo eventos esporádicos que são planejados pelas instituições organizadoras em parceria com as grandes redes, em especial de televisão, como a Liga Nacional de Basquete e a Superliga de Vôlei, os Jogos Pan-americanos, entre as principais competições.

Os noticiários, as propagandas e as transmissões, incluindo os canais por assinatura, estão direcionados aos eventos com alto investimento financeiro, como os torneios da Associação de Tenistas Profissionais (ATP), os campeonatos de futebol ligados à Fifa (como as ligas europeias), a Liga Norte-americana de Basquetebol (NBA), torneios de lutas de MMA (Mixed Martial Arts) como o UFC (Ultimate Fighting Championship) e de boxe do Conselho Mundial de Boxe (WBC), da Associação Mundial de Boxe (WBA), da Federação Internacional de Boxe (IBF), entre outras fortes entidades. Além disso, também são fomentadas a Liga Mundial Masculina e o Grand Prix Feminino de Vôlei, além dos circuitos mundiais de atletismo, natação, vôlei de praia, judô, surfe, ginástica, entre outros eventos internacionais de diversas modalidades.

Os campeonatos mundiais, como a copa do mundo de futebol e os jogos olímpicos de verão e inverno, incluindo as paraolimpíadas, formam o topo da pirâmide. A relação dos meios de comunicação com o desporto possui uma estratégia mercadológica interessante e lucrativa, ao multiplicar o número de 
interessados por eventos de alto rendimento, com apelo ainda para modalidades localizadas de outros países, como o futebol americano, que conquista adeptos por causa da cobertura periódica da televisão.

Mas, como implantar um projeto de comunicação esportiva olímpica?

Aprender com as grandes coberturas que, impulsionadas pela tradição, como no caso do futebol, do futsal e da fórmula um, ou mesmo por meio de conquistas, como o vôlei, a vela e a natação, determinam uma saída para a comunicação esportiva. Nesses casos, a atitude dos profissionais procura preservar, manter, divulgar e mesmo massificar determinada modalidade, como acontece com o futebol. A consequência é o estimulo à prática física e desportiva de algumas modalidades, fatores essenciais para minimizar problemas cotidianos, como os relacionados à saúde, ca exemplo da prevenção de doenças, e à educação. Com isso, o atual modelo da comunicação esportiva, baseado no excessivo fluxo de informações, necessita de outras dinâmicas profissionais, como as observadas por Isildinha Martins (2002, p. 5-6), com reflexos, especialmente, nas áreas de jornalismo e de relações públicas:

No esporte, é tudo muito rápido: lida-se com a vida dos atletas, pilotos, participantes e seus sonhos. A divulgação dos resultados, por exemplo, deve ser imediatamente após os feitos, tornando a assessoria de imprensa na área esportiva atípica no quesito horário de trabalho. Os eventos têm seus rituais de abertura e entrega de prêmios diferenciados, porém devem obedecer também ao cerimonial oficial e às regras de conduta em jogos desportivos. A comunidade desportiva e a imprensa são ávidas por informações antes dos fatos, tornando imprescindível um setor de relações públicas ou de comunicação, como observamos.

Se as principais redes de televisão conduzem os grandes eventos, principalmente os internacionais, por meio de acordos com poderosas entidades esportivas, como clubes e confederações, então cabe aos demais meios, particularmente os localizados fora dos grandes centros, estabelecerem uma outra dinâmica para a comunicação esportiva.

Esse planejamento determina a inclusão das organizações esportivas que são responsáveis pela gestão das modalidades com menor apelo midiático, como o levantamento de peso, o remo, o hóquei sobre grama, o badminton, entre outros esportes, inclusive os não-olímpicos, como o hóquei sobre patins ou o punhobol. Além disso, é fundamental a realização de trabalhos integrados entre as diversas vertentes, como pequenos meios (jornais, rádios, televisões, portais etc.), agências de publicidade e assessorias de relações públicas ou de comunicação. A gestão de projetos esportivos depende do trabalho coletivo entre as diversas áreas da comunicação, incluindo o comprometimento das organizações responsáveis pela gestão do desporto. O estudo do BNDES também propõe soluções para o desenvolvimento das demais modalidades, que indiretamente integram a comunicação: 
Desenvolver ações visando fomentar novas modalidades esportivas no país, a exemplo de diversos países que se esforçam em disseminar novos esportes. Incentivar a realização de torneios de exibição. No programas de incentivo ao esporte, exigir apoio a novas modalidades esportivas (Sanyos et al. 2007, p. 11).

Logo, o desenvolvimento do esporte em geral reflete diretamente na estrutura da comunicação esportiva, que necessitará de profissionais versáteis, com conhecimento sobre as diversas modalidades e também sobre as diversas áreas relacionadas, como educação física e o turismo. A ampliação da agenda esportiva para além do futebol, ocasionada pelo fluxo de informações (resultados, eventos etc.), também implicará uma mudança de comportamento na população. Isso especialmente em localidades onde certas modalidades têm impactos diretos, como Piraju, que começa a observar a necessidade de investimentos em praças esportivas e em profissionais da educação, entre eles o professor de educação física e do esporte.

\section{MEIO AMBIENTE E DESENVOLVIMENTO}

Atualmente, as questões ambientais têm recebido grande destaque na cobertura jornalística, com contribuições para a sua visibilidade e, por conseguinte, para a legitimação social. O binômio meio ambiente e turismo revelou uma grande oportunidade na viabilização de projetos de desenvolvimento regional relacionados à questão social e, nesse aspecto, os esportes assumem um formidável aparato calcado na inclusão social, principalmente dos jovens. Em Piraju, é possível argumentar sobre a existência de um trinômio: turismo, meio ambiente e esporte. A inter-relação dessas esferas tem possibilitado uma grande quantidade de financiamentos cruzados e projetos transversos, envolvendo aspectos locais da educação e da cultura, fatos que têm transformado a realidade de jovens na localidade.

Não de outra forma, as questões ambientais locais recebem uma formidável contribuição da canoagem no que tange à luta pela preservação ambiental. Nesse contexto, o tratamento que a cobertura jornalística tem dado aos treinos e às conquistas da equipe de canoagem foram imperativas para o indeferimento da construção de mais uma usina hidroelétrica, que alagaria as corredeiras onde são realizadas as provas. A equipe de canoagem conseguiu, por meio do esporte, aquilo que os ambientalistas não alcançaram em batalhas jurídicas: mudar o olhar da comunidade para a importância da manutenção das corredeiras (Cerveira Filho, 2007).

\section{PROPOSTAS PARA O DESENVOLVIMENTO DA ESTÂNCIA TURÍSTICA}

A cidade de Piraju, que foi condicionada como estância turística há quase uma década, ainda não contou com um grande impacto nesse setor da economia 
local. Certamente, precisa-se de investimentos que justifiquem tal status estancieiro. Sendo assim, muitas soluções estão para além do trabalho político de percepção desse ou daquele grupo de indivíduos sobre um determinado modelo de atividade turística. Residem na participação e na criatividade as ferramentas de envolvimento da população local e podem ser resolvidas seguindo o exemplo de outros roteiros turísticos do país, desde que atendidas as aptidões e condições de desenvolvimento local.

A primeira tarefa é planejar um mapa com destinos turísticos na região, incluindo todos os atrativos possíveis que podem ser utilizados pelos turistas. Tal mapa deve ser distribuído na cidade, como forma de intimizar o próprio habitante com os locais de visitação. Pode parecer estranho, mas pesquisas, entre elas a de Cerveira Filho (2007), apontam que muitos pirajuenses não conhecem diversos locais do município considerados como pontos turísticos. Alguns conhecem, mas não têm a percepção de um local turístico. Daí decorre um segundo momento: planejar a relação do habitante com o seu maior patrimônio, o rio Paranapanema.

Para tal intento será necessário criar espaços com segurança para os usuários, principalmente os banhistas, pois, afinal, são poucos os locais de acesso ao rio atualmente, restringindo-se praticamente à rampa para os barcos próxima ao bar Canto do Rio, à beira do Paranapanema. Ou seja, o único local para acesso de banhistas é na verdade de um local para acesso de barcos e não de pessoas, configurando-se em uma irregularidade que o poder público municipal insiste em não enxergar. Do outro lado da margem, o rio Paranapanema está praticamente cercado por grades que interferem no lazer da maioria da população, sendo restrito o acesso aos cerca de 3 mil sócios do Iate Clube Piraju, que é particular e o maior da cidade, em uma localidade de quase 30 mil habitantes.

Outras medidas necessárias são a limpeza dos principais pontos de lazer e a segurança, que precisam ser ampliados, com a demarcação de boias, raias e controle de velocidade dos barcos, de acordo com as regras de trânsito náutico interpostas pela Marinha e pela Capitania dos Portos. Ainda assim, o turista não se sentirá assistido, porque ele depende das pessoas, ou seja, da comunicação. Por isso, é muito importante realizar um trabalho de conscientização com a população que poderá acolher e orientar o visitante. A terceira tarefa é aumentar as opções de lazer. Os casarões e as sedes das antigas fazendas de café são atrativos ainda pouco explorados na comunidade. Muitas propriedades ainda possuem cachoeiras, lagos e trilhas. Esses espaços interessam aos visitantes que desconhecem a cultura e a natureza local. Abrir o acesso é interessante, gerando uma fonte de renda extra aos moradores da zona rural.

Em Piraju, um exemplo de roteiro interessante para se organizar poderia ser o das usinas hidroelétricas. O município possui uma rica história de relação com o setor elétrico, tendo se tornado autossuficiente em energia já no início do século XX. Atualmente, algumas usinas estão desativadas e se encontram 
em estado quase de abandono, como a UH Monte Alegre (primeira usina da cidade). A situação poderia ser revertida pela viabilização de um projeto turístico que construísse um roteiro contando a história das usinas e da história da região, como acontece em Corumbataí (SP).

Tabela 1: Usinas hidroelétricas de Piraju

\begin{tabular}{|c|c|}
\hline Entrada em operação & Usina hidroelétrica \\
\hline 1905 & Monte Alegre \\
\hline 1912 & Boa Vista \\
\hline 1917 & Salto do Palmital \\
\hline 1936 & Paranapanema \\
\hline 1957 & Paranapanema II \\
\hline 1962 & Jurumirim \\
\hline 1966 & Monte Alegre II \\
\hline 1971 & Paranapanema III \\
\hline 2002 & Piraju \\
\hline
\end{tabular}

Fonte: Cerveira Filho (2007)

O café e a pesca são símbolos de Piraju e, por isso, conduzem à quarta tarefa, puxada pela culinária, pelo artesanato, pela música, pelo teatro e por outras atividades culturais. O pescado poderá ser a base da gastronomia local, com pratos diferenciados servidos nos bares e restaurantes. A variedade de café local também deverá explorada, inclusive com o auxílio do sindicato rural, que pode instalar em sua sede um espaço para conhecimento e degustação das variedades do produto. Já o artesanato identificará o peixe e o café, sendo personalizados em suvenires e outras peças, com as vendas na feirinha, cada dia em uma praça. A canção não é a da mídia, mas a música urbana do interior, cantada pelos músicos da cidade. O teatro representará a cultura local, contando os causos locais. No carnaval, se segue a tradição das escolas de samba na folia de rua, mas também se deve levar em conta a cidade como um lugar de descanso. Além disso, ainda são destaque os belos jardins que marcaram a história de Piraju.

A parceria com as cidades vizinhas, principalmente Avaré e Águas de Santa Bárbara, é fundamental para o planejamento de excursões pelas agências de turismo, que também precisam ser ampliadas como forma de divulgar o local e facilitar a vinda de novos turistas. Assim como os parques, o serviço de guias é essencial, com o curso de preparação podendo ser oferecido pela prefeitura, 
em parceria com órgãos como a Secretaria de Esporte, Lazer e Turismo do Estado de São Paulo, o Serviço Brasileiro de Apoio às Micro e Pequenas Empresas (Sebrae), o Serviço Nacional de Aprendizagem Rural (Senar), entre outros.

São apenas algumas sugestões, entre várias, que os visitantes, incluindo os pesquisadores, ouvem quando estão em Piraju. Antes de tudo, a tarefa principal é reorganizar a cidade, com a preservação das ruas e calçadas antigas, assim como a estruturação de novas vias. O planejamento do centro comercial (com a criação de calçadão) é uma reivindicação antiga e precisa ser colocada em prática, sendo mais uma opção de lazer, inclusive noturna. A instalação de uma universidade pública, no caso, um campus da Universidade Estadual Paulista Júlio de Mesquita Filho (Unesp) ${ }^{6}$, com cursos de geologia e turismo, por exemplo, atrairia um público diferenciado, fato que auxiliaria no desenvolvimento da região. Porém, o ponto mais importante deve ser o de melhorar a condição de vida do habitante local, que necessita visitar os pontos turísticos e fazer da sua cidade uma forma de lazer e de trabalho. Uma das alternativas para se conhecer e destacar o município é valorizar projetos relacionados à canoagem.

\section{A CANOAGEM EM PIRAJU?}

A Associação Pirajuense de Esportes Náuticos (Apen) foi criada em 8 de março de 2004. É uma associação civil de direto privado sem fins econômicos, de duração por tempo indeterminado, com sede e foro no município da Estância Turística de Piraju. A entidade foi constituída para garantir a realização de um projeto iniciado em 2001, por meio de uma parceria entre a CBCa Confederação Brasileira de Canoagem (CBCa) e uma empresa concessionária de energia hidrelétrica, para construção de um Centro Esportivo de Alta Performance (Ceap). A iniciativa proporcionou as condições necessárias para abrigar a sede de treinamentos da Seleção Brasileira de Canoagem, o que efetivamente ocorreu de 2001 a 2004.

A Apen, portanto, independente da vontade política, proporcionou condições para que crianças em risco social pudessem conhecer a modalidade canoagem (velocidade e slalom), inserindo-as na sociedade, elevando a autoestima e propiciando a expectativa real de um futuro promissor, seja no esporte ou na sociedade. Também, contribuiu para o surgimento de dezenas de atletas no cenário do país, vários deles com conquistas nacionais e internacionais. A coroação desse trabalho, desenvolvido pela Apen em Piraju, foi a participação de uma aluna da zona rural como a primeira mulher atleta a representar o Brasil

6 Criada em 1976, a Universidade Estadual Júlio Mesquita Filho (Unesp) possui diversos campi, com preferência no interior paulista. Fonte: <www.unesp.br/historico>. Acesso em: 26/10/2011.

7 0s dados sobre a canoagem em Piraju foram enviados por Gervásio Pozza Filho e Margareth Pillegi Mourão, do Departamento de Turismo e Atividades Náuticas da Estância Turísitica de Piraju. 
numa olimpíada (a de Beijin, em 2008) - Poliana Aparecida de Paula. A última conquista da Apen foi o Campeonato Brasileiro de Slalom, realizado em Piraju, nos dias 17 e 18 de dezembro de 2011.

Também como reflexo do trabalho da entidade, é possível apontar que, quando da elaboração do presente trabalho, em agosto de 2011, nada menos que oito atletas pirajuenses estavam participando de treinamento para disputas internacionais. Poliana de Paula, Charles Correa, Anderson Oliveira e Pedro Henrique Gonçalves treinavam para competições europeias que decidirão vagas brasileiras para a Olimpíada de Londres (2012), da modalidade slalom. Patrick de Almeida, atleta paraolímpico, participava do Para-Mundial em Budapeste, na Hungria. Os irmãos Rodrigo e Roberto Cabral e João Carlos Rodrigues fazem parte da equipe permanente da Seleção Brasileira de Canoagem de Velocidade.

A principal missão da entidade, na parceria com a prefeitura (que arca com o custo dos projetos e da Escola de Canoagem), é a inserção social de crianças e jovens, utilizando a canoagem (slalom e de velocidade) como instrumento de desenvolvimento desportivo, ambiental e intelectual dos atletas. A meta é a representação brasileira nos Jogos Olímpicos de 2016, buscando sempre atingir o nível de excelência nos eventos nacionais e internacionais. Os atletas e voluntários desse projeto devem inspirar a sociedade, em especial os jovens, a adotar os ideais olímpicos e aspirar sempre à excelência no esporte e em suas vidas.

Espírito esportivo, virtude educacionais, responsabilidade ambiental, proteção à saúde, segurança, bem-estar físico e mental, igualdade, participação de todos, solidariedade, respeito pelos outros, autodescoberta, autoafirmação, amor pelo desafio físico e mental, precisão e perseverança são alguns dos princípios do olimpismo, que foram contemplados na história da entidade, como provam os resultados alcançados, e são mantidos como principais valores. Lembramo-nos da frase da frase do criador dos jogos olímpicos modernos, Pierre de Coubertin, dita em 1918 (apud Chang, 2001, p. 1): "Se alguém me perguntar qual é a receita para viver com espírito olímpico, eu respondo que a primeira condição para isso é ser feliz".

\section{Projetos}

\section{Talentos das águas}

Iniciado em janeiro de 2011, esse projeto está inserido como manifestação desportiva de alto rendimento e faz parte das ações que receberão o "selo de qualidade” implantado pela Confederação Brasileira de Canoagem (CBCa), visando ao aumento quantitativo e qualitativo de atletas brasileiros para os Jogos Olímpicos de 2016. Tem duração proposta até 2016 e sua meta é contribuir para o surgimento de talentos em condições técnicas para representar o Brasil na Olimpíada do Rio de Janeiro (2016), que serão revelados em competições 
nacionais de iniciantes, conforme calendário da CBCa. Os atletas integrantes do projeto pertencem à rede de ensino municipal da Estância Turística de Piraju e treinam no contraturno escolar.

O projeto atende até cem atletas, divididos em dez turmas, visando à busca incessante do talento. Embora as parcerias sejam com escolas públicas do município, escolhidas de forma estratégica (mais próximas aos locais de treinos), isso não impede que um aluno de escola privada possa fazer parte do projeto, o que acontece. O parceiro principal é o Comitê Olímpico Brasileiro (COB), por meio do Ministério do Esporte e da CBCa.

No Campeonato Brasileiro de Iniciantes, realizado em Foz do Iguaçu (PR) entre 26 e 28 de agosto de 2011, a equipe pirajuense de slalom comprovou a vocação olímpica, alcançando o primeiro lugar na classificação final, além de ter os três primeiros atletas iniciantes premiados, tanto na categoria masculina, quanto na feminina.

\section{Navega São Paulo}

Trata-se de um projeto iniciado em 2010 e desenvolvido até junho pela Apen e que seria retomado em outubro de 2011. Objetiva democratizar o acesso às modalidades náuticas de vela, remo e canoagem (slalom e de velocidade), promovendo a inserção social e ambiental, propiciando a iniciação de alunos da rede pública de ensino nquelas modalidades. O principal parceiro é a Secretaria Estadual de Esporte, Lazer e Juventude, com apoio de diversas empresas e autarquias, por meio de dedução fiscal no imposto de renda.

\section{Escola Municipal de Canoagem}

Esse projeto é desenvolvido com orçamento próprio da prefeitura municipal, mas é carente de recursos e estrutura para atendimento da demanda, aquisição de equipamentos e para contratação de profissionais habilitados.

\section{Público beneficiado}

Os projetos se voltam a crianças e jovens na faixa etária de 10 a 29 anos, especialmente aqueles da rede pública de ensino, oriundos de famílias carentes, em situação de risco e em vulnerabilidade social, sem grandes expectativas ou oportunidades de crescimento pessoal, social, educacional ou profissional.

Os projetos proporcionaram, além do surgimento de novos talentos no cenário nacional, a oportunidade de crianças e jovens, hoje adultos, se transformarem em profissionais qualificados, dentro e fora da área esportiva. Somados todos os projetos, Piraju tem cerca de 110 crianças, jovens e adultos praticando a canoagem, de alunos iniciantes a atletas olímpicos. 
Mais de mil pessoas, especialmente crianças, já foram beneficiados com o projeto da Escola Municipal de Canoagem. Indiretamente, mais de 3 mil pessoas, notadamente as famílias dos alunos, tiveram impacto positivo do projeto, seja esportivo, social, educacional-cultural, financeiro ou de saúde. Na comunidade, eliminaou-se a ocorrência de mortes por afogamento, reduziram-se os índices de criminalidade infantil e desenvolveu-se uma consciência maior em relação aos vícios, o que minimizou os problemas de utilização de drogas.

\section{Locais das atividades}

As atividades desportivas são executadas no Centro de Fomento Turístico Prefeito Cláudio Dardes, no Centro Esportivo de Alta Performance (Ceap) e na Praça Gilberto Polenghi, todas áreas públicas municipais às margens do rio Paranapanema, onde estão localizados os trechos naturais (corredeiras - adequadas à prática esportiva da modalidade slalom) e represados (adequados à prática da modalidade de velocidade), ambos palcos de campeonatos estaduais e nacionais.

\section{CONSIDERAÇÕES FINAIS}

Em Piraju, os meios de comunicação têm a canoagem como pauta rotineira em seus noticiários, da mesma forma que os assuntos sobre futebol, e isso já seria uma grande novidade para relembrar o mito de que o brasileiro ainda vive o mito do "país do futebol". A constituição da educação pela atividade física, aliada aos valores olímpicos e do esporte, conduz indiretamente a agenda da mídia local, determinando impactos significativos na cidade, como no caso da preservação ambiental. As parcerias estabelecidas entre a iniciativa privada, as organizações esportivas e o setor público foram fundamentais para o desenvolvimento da canoagem. Com isso, existem reflexos também na área de comunicação, com o trabalho desenvolvido ainda pelo Departamento de Turismo e Atividades Náuticas da Estância Turística de Piraju, que possui um espaço de divulgação e de assessoria à imprensa local.

O município, como outros tantos de parca receita, precisa de investimentos, como foi apontado ao longo do texto, que são determinantes para a manutenção do status de estância turística, bem como para a valorização do turismo e, por conseguinte, do bem-estar da população. A possibilidade de se associar turismo, esporte, comunicação e proteção dos recursos naturais encontra uma via positiva em Piraju, fazendo com que os habitantes reinterpretem a significação de suas paisagens naturais, revalorizando-as em termos de preservação, endossados pelo lazer e alicerçados nos valores do esporte. A experiência da canoagem é um modelo a ser seguido por outras localidades que, ao se aproximarem das entidades representativas de modalidades com pouco apelo midiático, conquistarão espaço no movimento olímpico, avalanche que certamente preencherá o noticiário brasileiro até 2016. 


\section{REFERÊNCIAS}

BARON, Catherine. La gouvernance: débats autour d'un concept polysémique. Revue Droit et Société, n. 54, p. 329-351, jun. 2003.

CERVEIRA FILHO, José Luiz F. Pós-modernidade e risco na bacia hidrográfica do Alto Paranapanema: uma análise da construção social da sub-política ambiental no município de Piraju (SP). Tese (Doutorado em Ciências Sociais) - Universidade Federal de São Carlos, 2007.

COB. Olimpismo: suas origens e ideais. Rio de Janeiro: Comitê Olímpico Brasileiro, 2010. Disponível em: <http://www.cob.org. br/movimento olimpico/olimpismo.asp >. Acesso em: 20 ago. 2011.

CHANG, Francisco. Jornalismo olímpico. In: COSTA, Lamartine Pereira da; HATZIDAKIS, Georgios Stylianos. Estudos olímpicos 2011. Coletânea de Textos. Texto n. 11. São Paulo: Grupo de Estudos Olímpicos da Uniban, 2001. Disponível em: <http://www. cob.org.br/pesquisa_estudo/academia_todos_artigos.asp >. Acesso em: 25 ago. 2011.

GURGEL, Anderson. Futebol S/A: a economia em campo. São Paulo: Saraiva, 2009.

MALULY, L. V. B. Jornalismo esportivo: desafios e propostas. In: CONGRESSO BRASILEIRO DE CIÊNCIAS DA COMUNICAÇÃO, XXXIII, Caxias do Sul (RS), 02-06/09/2010. Anais... São Paulo: Intercom, 2010. Disponível em: <http://www.intercom.org.br/ papers/nacionais/2010/resumos/R5-1779-1.pdf > . Acesso em: 31 ago. 2011.

MARQUES, José Carlos. Comunicação e esporte: diálogos possíveis. São Paulo: Artcolor, 2007.

MARQUES, José Carlos; TOLEDO, Vera R. Carvalho; CARVALHO, Sérgio (Org.). Comunicação e esporte: tendências. Santa Maria (RS): Pallotti, 2005.

MARTINS, Isildinha. A comunicação nas organizações desportivas no Brasil: profissionais e instrumentos. Tese (Doutorado em Comunicação Social) - Umesp, São Bernardo do Campo, 2006.

. A comunicação nas organizações desportivas. In: CONGRESSO BRASILEIRO DE CIÊNCIAS DA COMUNICAÇÃO, XXV, Salvador, 01 a 05/09/2002. Anais... São Paulo: Intercom, 2002.

SANTOS, Angela Maria M. Martins et al. Esportes no Brasil: situação atual e propostas para desenvolvimento. Brasília: BNDES, 2007. Disponível em: <www.bndes.gov.br/SiteBNDES/export/sites/default/.../esporte.pdf>. Acesso em: 25 out. 2011.

SEADE. Atlas Seade da Economia Paulista. São Paulo: Seade - Fundação Sistema Estadual de Análise de Dados, 2006. Disponível em: <http://www.seade.gov.br/produtos/atlasecon/> Acesso em: 26 out. 2011.

TUBINO, Manoel. 0 que é olimpismo. São Paulo: Brasiliense, 2007.

Recebido em: 06.09.2011 / Aceito em: 04.11.2011 